sciendo Порівняльна професійна педагогіка 8(2)/2018 Comparative Professional Pedagogy 8(2)/2018

DOI: $10.2478 /$ rpp-2018-0026

Doctor of PE and Sports Pedagogy, Researcher, ABDULLAH BORA ÖZKARA Erzurum Technical University, Turkey Address: 25100-Yakutiye/Erzurum, Turkey E-mail: boraozkara@gmail.com

\title{
PHYSICAL EDUCATION IN EU SCHOOLS AND TURKEY: A COMPARATIVE STUDY
}

\begin{abstract}
The foundations of modern physical education in Turkey have been defined using arrangements of European countries. In general, it has been determined that European standards are taken into account as criteria when physical education is generally assessed. The evaluation of this development should also be made with scientific studies. It cannot be said that the researches carried out by the comparative research method are not sufficient; besides, many studies are carried out in different fields of physical education in Turkey. In this research the current status of physical education has been analyzed through comparative research methodology. Core aims of the study include assessing the value of $P E$ to learners and the community; finding out and comparing teaching modules and approaches; comparing material environment around teaching PE; defining the modern trends in physical education development. Data have been collected by means of document analysis. Curriculum reform carried out in 2013 in Turkey was accepted as the start for the conducting of the document analysis. As a result, it must be accepted that Europe is an established physical education course culture. Turkey has been carrying out the reforms in recent years to create this culture. Europe has a strong heritage in terms of physical education while Turkey has increased its efforts in recent years to build this heritage. It has been revealed that the new physical education course content has been used in Turkey since 2004. Physical education and sports programs are designed on two basic areas of learning and development: mobility competence and active and healthy living. The basic structure of the physical education lesson teaching plan is based on the principles of physical, mental, individual, emotional and social skills, taking into account the environmental conditions and prevalence of providing physical activity and participation of students in sports.
\end{abstract}

Keywords: comparative study, physical education, curriculum, sports, teacher education, Turkey, European countries.

\section{INTRODUCTION}

National and international organizations as well as non-governmental organizations have been carrying out many researches in recent years, emphasizing the importance of comparative cross-sectional research on education (European Commission, 2014; Langford et al., 2015; UNESCO, 2014). In recent years, with the increasing number of social and health problems caused by sedentary life, comparative studies are also increasing in the field of physical education (Biernat, \& Piątkowska, 2013). Physical exercise as instituted in the physical education syllabusis not only a key factor in pupils and students' physical fitness and good health, but also fundamental in enabling them perform 
sciendo Порівняльна професійна педагогіка 8(2)/2018

Comparative Professional Pedagogy 8(2)/2018

better in curricular activities (European Commission, 2013; Alemdağ \& Alemdağ, 2015). Lately, there has been a growing concern regarding the quality of Physical Education standards in EU countries. The observation has consequently triggered a series of in-depth research studies to query the state of affair, and find meaningful deduction (Langøien et al., 2017). At the same time, concern about the curriculum of physical education in Turkey is increasing. To find solutions to these criticisms, Turkey has undergone substantial changes in the physical education curriculum by the Ministry of National Education in 2013 (Turkish Ministry of National Education, 2017). Regardless of the fact that PE in Europe is not standardized across all the nations, a keen look across the region reveals predictable patterns featuring different levels of infrastructure endowment, human resource deployment and policy design (Krüger, \& Hofmann, 2015). Also researches on the structure of the Turkish physical education course and the reforms carried out are not found at sufficient level.

\section{THE AIM OF THE STUDY}

This paper, therefore seeks to understand the nature and evolution of PE in European countries and Turkey, with the perspective of inferring notable conclusions that could be of value to stakeholders and researchers in the field.

Having a huge focus on both the qualitative and quantitative value of the subject, the study centers around exploring the traditional and evolutional perspectives in the administration of PE in European and Turkish schools. Core aims of the study include, but not limited to: 1) evaluating the value of PE to learners and the community; 2) finding out and comparing teaching modules and approaches; 3 ) comparing material environment around teaching PE; 4) lastly, the study seeks to understand the distribution of the trends.

\section{THEORETICAL FRAMEWORK AND RESEARCH METHODS}

Document analysis and document review were used as methods of data collection for this study within the context of descriptive approach. In this study, the discipline of physical education in Turkey and European countries was compared by using the preferred document analysis method in comparative studies (Rebryna, 2014). Data was obtained from journal articles and whitepapers accesses from reputable websites and research repositories. The online resources reflect information collected over the past 8 years, some with earlier references. Multiple data collecting techniques were employed in these and scholarly articles.

Physical education is a mandatory subject in almost all EU countries and plays an important role in fostering learner's social, physical and personal development. With most pupils and students learning PE ranging mostly in teenage, the subject follows a pragmatic and learner-centered approach. The paper acknowledges that the EU lacks explicit and solid regulations or a centralized governing council for educational matters, meaning that the article pursues the subject of PE through individual countries' framework (European Commission, 2013). But it can be said that European countries have a stable structure in applying educational policies. It is somewhat debatable to talk about this stable structure for Turkey. Physical education has a central structure and everyone is offered equal opportunity to learn in Turkey. Physical education activities in European countries are also supported outside the school (OECD, 2015). Participation in non-school courses and sports organizations is regularly supported. Participation in non-school sports activities has not a long history in Turkey. The developments in this field have been supported for the last 10 years and the infrastructure for participating in sports activities outside of school is starting to be established. 


\section{RESULTS}

Qualification of PE teachers. In most EU countries, primary schools' PE tutors must have a threshold bachelor's degree while their secondary school counterparts have master's degree in education and sports related program (Vlcek, 2009). Master's degree is not required to become a physical education teacher for all school levels in Turkey. In general, both in Europe and Turkey classroom teachers are engaged in physical education classes. However, in countries such as Germany, France and Ireland, a classroom teacher can be assisted by a sports coach or a counselor employed at school, or a specialist teacher like in Slovenia. Contrary to Europe, physical education classes in public schools can be processed only with classroom teachers in Turkey. In general, the entire middle and high school physical education classes in most European countries and Turkey are conducted by qualified physical education teachers. In schools in Denmark, Iceland and Norway, it can be seen that classroom teachers conduct physical education classes. Graduates of the coaching education and sports management program can also be physical education teachers in Turkey. After graduation, candidates who have received training for two semesters can use the title of physical education teacher.All throughout EU, documents that the tutors take up quality assessment tests periodically to be aligned to the dynamics of the fieldare required (UNESCO, 2014). From this point of view, it can be said that teachers in Europe have a plan in terms of corresponding to and improving the standards. In Turkey this process is not quite the same as in Europe. Institutions such as teacher academies have started to work on the development and supervision of the development (Jones, \& Green, 2017; Kiekens et al., 2016).

Teachers' salaries are undoubtedly important for quality education. In Belgium, Austria, France, Spain, Portugal and UK, specialist teachers are given higher priority and salary in employment to teach PE. As a result, the level of education is comparatively different, with countries like Ireland and Finland recording better PE standards. The direct link between teacher qualification and remuneration leads us to the issue of salaries, which are anyway directly proportional. Switzerland pays the most, with the highest being $\$ 68,000$ annually, followed by Netherlands, Germany and Belgium. The UK is a mild payer, rounding up to $\$ 44,000$ annually (European Commission on Education, 2013). In fact, teachers' salaries should be assessed on a gross national income basis, rather than numerically. If to take into consideration the perspective in primary and secondary schools in 21 OECD countries, Turkey takes the 23rd place. Turkey at all three levels is below the OECD average. The highest salaries are Luxembourg, Switzerland and Germany; the lowest are in Latvia (UNESCO, 2014). But it can be said that the salaries have increased gradually since the beginning of 2000 for Turkey. Many PE teachers earn additional income from teaching or performing other work in their spare time. The state supports teachers in this regard (Turkish Ministry of National Education, 2017; Turkish Public Health Authority, 2014).

Weekly course hours. According to the American National Academy of Science, a quality physical education program must consist of at least 225 minutes per week, 45 minutes per course, in the context of a licensed physical education teacher. InIreland, PE classes have a designated 1.33 hours per week, which includes gymnastics, swimming, indoor events and class time. The rate compares inferiorly with Portugal where PE is exclusively allocated over two hours per week, the same is about the UK (European Commission, 2013). One reason of the fact that countries allocate less time to PE is that they state that parents 
sciendo Порівняльна професійна педагогіка 8(2)/2018

Comparative Professional Pedagogy 8(2)/2018

should take up the task by engaging their children in physical exercise at home. Ordinarily, 70 hours per year is the standard annual time for PE as required by the 2009 Lisbon Treaty and it makesthe value system in European sport education. However, some countries, like Latvia and Cyprus, do have a flexible time schedule for PE, with the school head and management able to slightly adjust between 45 to 60 minutes per week (European Commission, 2013). In Turkey, the time allocated to physical education classes in schools in 2013 was determined as 80 minutes. However, after 2013, an education reform including physical education and sports curriculum has been put into effect. Thus, in elementary and secondary schools the physical education course hours totaled to 160 minutes, adding 2 hours of elective courses in addition to the standard course of 2 hours per week. When it is thought that the average physical education lesson hours is 105 minutes in European countries, there seems to be an important educational reforms carried out in Turkey for PE course hours (Turkish Public Health Authority, 2014).

Curriculum content. One can observe that throughout Europe the curriculum for PE has been gradually evolving along factors such as physical and cultural environment. For instance, in Croatia PE lessons began with short course, then morphed into gymnastics before the mandatory and formally structured primary and high school modules were introduced. This illustrates the versatile and accommodative nature of PE, as UNESCO (2014) suggests that more than half of the 27 European countries, covered by the study, make occasional adjustments to the curriculum to make it more relevant. In Turkey physical education course content was designed to serve military purposes in the early republican period, because the number of modern physical education course specialists in that period was limited. In European physical education physiology, anatomy, psychology and biology was considered appropriately. This opinion began to settle with the republican period in Turkey.

In Europe, the content of physical education classes in recent years has included topics such as healthy life and obesity prevention and treatment. By default, physical education is meant to not only to promote physical health but also bolster talent among the youngsters. Similarly, this factor exhibits a varying degree of blend between the PE curriculum and sporting opportunities that help learners actualize their sporting talents. For this reason, schools have a coherent commitment to sports clubs. For example, in the UK, as Bailey reports, physical education provides linkage to professional sports as early as to 10 year olds. This implies that sporting institutions take care of curricular development and practice. However, the contrary is with most European states, with countries like Greece, Hungary and Sweden reportedly running a PE curriculum which is not in tandem with sporting institutions, according to a 2012 study. Turkey is in need of development cooperationbetween schools and sports clubs, because students have to make a choice between schools and sports if this cooperation is inadequate.

Considering the pragmatic nature of $\mathrm{PE}$, slight changes in culture and socioeconomicshave necessitated a revision of the PE syllabus in over 15 European countries including Czech, Hungary and Finland, according to the PREVOB project report. Report on the School-Based Intervention to promote physical activity of children aged 1113 in the UK reveals that inclusion of PE for the disabled is one of the most notable reforms that European nations are embracing. Curriculum development efforts, at least in theory, are taken very seriously in Turkey. But it is important to remember that the curriculum is valid only within the school boundaries. There is a need for time to incorporate the difference in understanding acquired from the curriculum development. 
Since 2014, a new physical education course content is used in Turkey. Physical education and sports programs are designed on two basic areas of learning and development: mobility competence and active and healthy living. The basic structure of the physical education lesson teaching plan is based on the principles of physical, mental, individual, emotional and social skills, taking into account the environmental conditions and prevalence of providing physical activity and participation of students in sports.

Challenges. A number of common stressors consistently undermine the practice of PE in European schools. Teachers need to be aware of their being valuable. Similar is the case in Turkey. Regardless of the individual problems faced by each country, the material and cultural environment is the major frustration. In addition, a growing body of information closely relates to social factors (mainly emotion and personality) affecting adolescents to the reception of PE by learners. Turkey as well as other European countries feels concern that there is a tendency removing students from physical education activities. It is observed that other lessons were performed during physical education class hours, especially with the pressure of the families and school administrations. Authorities are trying to avoid this situation. As a precautionary measure, different assessment tools were put into operation by removing the central exams that students had to enter. It is aimed at students being more active in physical education classes without being directed to other courses.

In the past years, there were considerable obstacles to physical education lessons with problems such as lack of equipment, nutrition and poverty. Lack of essential equipment severely cripples physical education practice. Malnutrition is abold threat, since it makes children not strong enough, or uninterested in taking PE classes. It also promotes uneven achievement of PE goals. Transportation and nutrition assistance to students in order to avoid this situation in Turkey is made by Ministry of Education. In Bulgaria, the national policy on education still undervalues PE, which results in understaffing and less funding on PE facilities. In UK, PE is regressively less physical, which poses threat to its role in schools. Turkey and European countries have some common challenges. Considering Turkey's geographical location and population, it is quite clear that it has to overcome peculiar problems. Turkey has the largest refugee population is modern Europe. This requires taking into account the issue of adaptation in the planning of physical education courses.

\section{CONCLUSIONS}

The core aim of this paper is to illustrate the state of Physical Education in Europe and Turkey in both material and structural viewpoint with intent of establishing its current status quo. Evidently, physical education as a curricular subject, fits different but not much divergent statuses in European schools. The study concludes that in some European countries (the UK, Denmark and Finland), physical education is valued more than in others (European Commission, 2014).Turkey has laid the foundations of modern physical education inspired by Europe. But it is debatable whether physical education and sports environment with European standards have been reached in the process up till now. It is difficult to clarify this situation. For this to happen, the consequences of the reforms made in recent years should be anticipated and reforms must be carried out steadily. There is no sufficient number of comparative studies in physical education in Turkey. From this perspective physical education lessons were considered as a whole in this research. Having highlighted the fundamental ideas defining the subject across the continent and Turkey, the paper ascertains the acute need for harmonizing conditions. 
sciendo Порівняльна професійна педагогіка 8(2)/2018

Comparative Professional Pedagogy 8(2)/2018

Prospects of further research in this area include elaborating basis necessary for these harmonizing conditions implementation in Turkish schools and providing environment encouraging physical education development.

\section{REFERENCES}

1. Alemdağ, C., \& Alemdağ, S. (2015). Cheating behaviors of school of physical education and sport students. International Journal of Science Culture and Sport (IntJSCS), (Issue 3). Retrieved from: https://doi.org/10.14486/IJSCS292.

2. Bidyuk, N., \& Ikonnikova, M. (2017). Comparative pedagogical analysis of philologists' professional training at American and Ukrainian universities. Comparative Professional Pedagogy, 7 (3), 7-13.

3. Biernat, E., \& Piątkowska, M. (2013). Comparative leisure physical activity: a comparison between Polish and European population. Physical Culture and Sport. Studies and Research, 51 (1), 33-41. Retrieved from https://doi.org/10.2478/pcssr-2013-0019.

4. Bowen, G. A. (2009). Document analysis as a qualitative research method. Qualitative Research Journal, 9 (2), 27-40.

5. European Commission. (2013). PE and sport at school in Europe. Luxembourg.

6. European Commission. (2014). Special Eurobarometer 412 sport and physical activity. Brussels.

7. European Commission/EACEA/Eurydice. (2013). Physical education and sport at school in Europe. Luxembourg.

8. Jones, L., \& Green, K. (2017). Who teaches primary physical education? Change and transformation through the eyes of subject leaders. Sport, Education and Society, 22 (6), 759-771.

9. Kiekens, C., Moyaert, M., Ceravolo, M. G., Moslavac, S., Juocevicius, A., Christodoulou, N., \& Negrini, S. (2016). Education of physical and rehabilitation medicine specialists across Europe: a call for harmonization. European Journal of Physical and Rehabilitation Medicine, 52 (6), 881-886.

10. Krüger, M., \& R. Hofmann, A. (2015). The development of physical-education institutions in Europe: A short introduction. The International Journal of the History of Sport, 32 (6), 737-739.

11. Langford, R., Bonell, C., Jones, H., Pouliou, T., Murphy, S., Waters, E., \& Campbell, R. (2015). The World Health Organization's health promoting schools framework: a Cochrane systematic review and meta-analysis. BMC Public Health, 15 (1), 130.

12. Langøien, L. J., Terragni, L., Rugseth, G., Nicolaou, M., Holdsworth, M., Stronks, K., ... Roos, G. (2017). Systematic mapping review of the factors influencing physical activity and sedentary behaviour in ethnic minority groups in Europe: a DEDIPAC study. International Journal of Behavioral Nutrition and Physical Activity, 14 (1), 14-99.

13. OECD. (2015). Health at a glance 2015. Paris: OECD Publishing.

14. Rebryna, A. (2014). Analysis of national and foreign specialized sport education for senior pupils. Comparative Professional Pedagogy, 4 (1), 59-67.

15. Turkish Ministry of National Education. (2017). Müfredat. Ankara.

16. Turkish Public Health Authority. (2014). Tukish NHA. Ankara.

17. UNESCO. (2014). World-wide Survey of School Physical Education. Paris.

18. Vlcek, P. (2011). A comparison of physical education (PE) development in the Czech Republic, Germany, and the USA - a historical perspective. Gymnasium, 41 (1), 51-59. 